\title{
Implementation of the Technological Plan for Education in Portugal, a School Perspective
}

\author{
António Castro $^{1}$ and Leonel Santos ${ }^{2}$ \\ ${ }^{1}$ Secondary School Fontes Pereira de Melo, PTE Coordenator, Rua O Primerio de Janeiro, \\ 4100-366 Porto - Portugal \\ atc@meo.pt \\ ${ }^{2}$ Algoritmi Center, University of Minho, Campus de Azurem, 4800-058 Guimarães - Portugal \\ leonel@dsi.uminho.pt
}

\begin{abstract}
The Portuguese Ministry of Education has intervened in the Technologies and Information Systems (TIS) of the educational system with a Technological Plan for Education (TPE). The TPE is the Portuguese initiative for ICT in education, and is an intervention in three axis - Technology axis, Contents and Training which cover in an integrated and transverse way all areas related to the modernization of the educational system in Portugal. The full impact generated by this action is of particular importance due to the high performance enabled by the integration of ICT in the management and quality of the educational system thus allowing for an increase in confidence, performance and competitiveness. In this paper we follow a model in the implementation of the TPE in secondary schools. It shows a solution we came up. A strategic plan and is iterative assessment, from the need to address this problem.
\end{abstract}

Keywords: Educational Information Systems, Strategic planning, training and professional development, educational management and information technologies.

\section{Introduction}

The Technological Plan for Education, a program for the technological modernization of the Portuguese school, is a decisive turning point towards what really matters in schools: teaching and learning. The TPE aims to make school a place for interactivity and the sharing of knowledge without barriers, to certify the ICT skills of teachers, students and staff and to prepare youngsters for the knowledge society. The aim of the TPE is to put Portugal among the five most advanced European countries in terms of technological modernization of schools by 2010 (Table 1).

Table 1. TPE Goals - Source: www.pte.gov.pt

\begin{tabular}{|l|c|}
\hline \multicolumn{1}{|c|}{ GOALS } & 2010 \\
\hline High-speed Broadband Internet connection & $48 \mathrm{Mbps}$ \\
\hline Number of students per PC with internet connection & 2 \\
\hline Percentage of teachers with ICT certification & $90 \%$ \\
\hline
\end{tabular}

A. Tatnall, O.C. Kereteletswe, and A. Visscher (Eds.): ITEM 2010, IFIP AICT 348, pp. 75-85, 2011.

(C) IFIP International Federation for Information Processing 2011 


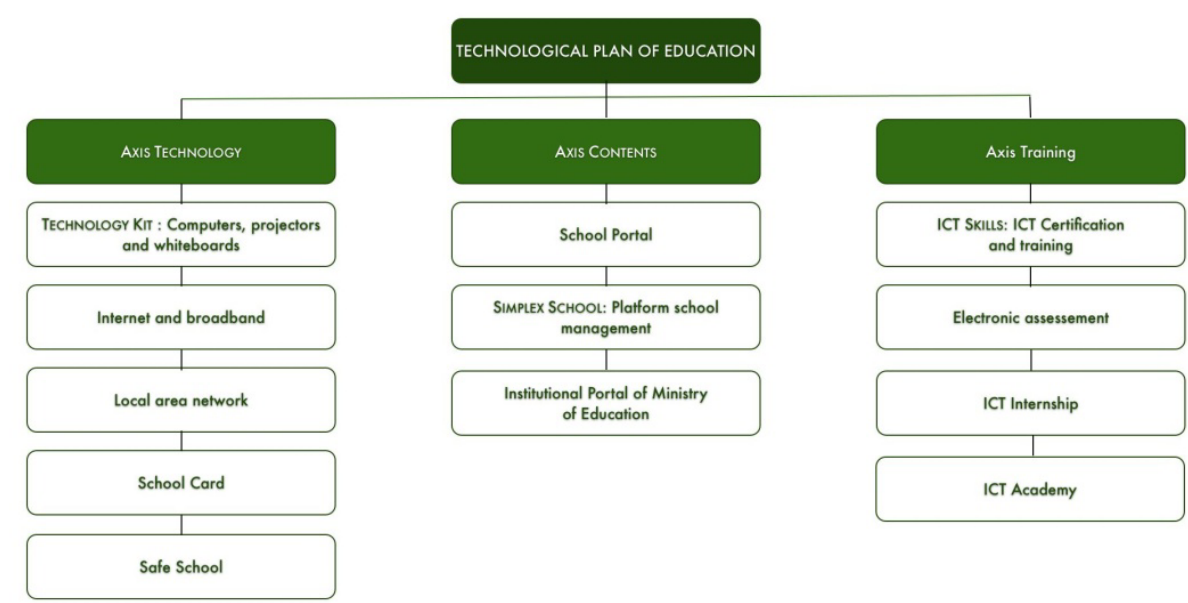

Fig. 1. Technological Plan for Education Source: www.pte.gov.pt

The Technological Plan for Education comprises three areas of action Technology, Contents and Training, which act in an integrated and cross manner in the Portuguese education system. As shown in Figure 1, each axis has its own projects with objectives and participants.

TECHNOLOGICAL KIT - Interactive whiteboards, computers connected to de Internet, and video projectors: Reinforce IT equipment in the classroom. Goals: 2 students per computer in 2010, to improve the ratio of students per computer connected to broadband Internet. To increase the amount of support equipment.

HIGH SPEED BROADBAND INTERNET: To increase the rate of broadband Internet access among schools to at least 48Mbps by 2010. Goals: To progressively increase the minimum speed of Internet connection in schools to 4 Mbps in 2007 and 48 Mbps by 2010. To ensure the ubiquity and safety of access.

LOCAL AREA NETWORKS: To ensure Internet access in all classroom and school spaces. Goals: To allow students and teachers to have Internet access in the classrooms. To enable computerisation of school management.

SCHOOL CARD PROJECT: Generalise to use the student's e-cards whit several functionalities such as, access control, attendance record and electronic purse. Goals: to increase efficiency and safety in schools.

\section{- CONTENT AXIS -}

SCHOOL PORTAL PROJECT: Create a school portal with a content sharing, distance learning and cooperative functions. Goals: to increase the production, distribution and use of digital contents ( for instance exercises, textbooks, electronic notebooks). To encourage the development of student's e-portfolio. To complement conventional teaching methods and increment interactive teaching and continuous learning practices.

SIMPLEX SCHOOL PROJECT: To create an electronic platform for school management. Goals: to increase efficiency in management and communication between the agents in scholar community. To improve access to school information. 


\section{- TRAINING AXIS -}

ICT COMPETENCIES TRAINING AND CERTIFICATION PROJECT: To create programmes for modular and progressive certification in ICT competencies. ICT training programme for teachers and non-teaching staff aimed at the certification of competencies. Goals: generalise ICT skills training and certification. To promote the use of ICT in teaching and management.

ELECTRONIC ASSESSMENT PROJECT: To use the computers in student assessment (Diagnostic, Formative and summative assessment). Goals: Promote the educational use of ICT.

ICT INTERNSHIP PROJECT: Internship aiming at providing specific training at workplace for ICT vocational education students in reference national and international technological companies. Goals, to promote excellence and employment opportunities for ICT vocational students.

\section{Source: Technological Plan for Education}

The use of school information systems provides coordinating mechanisms for the central educational authorities, so they can monitor what schools are producing [1].

In what schools are concerned, at this stage of gradual implementation of the TPE in the field, a study that sought to clarify the existing conditions was developed, with the aim to provide information, for strategic decision making, in the monitoring of the implementation of the TPE in schools.

The problematic of the adequate use of technology in education cannot be answered only by introducing more technology in the educational system. Having technology at hand is not a good enough reason for schools to rely comfortably in its use. It was the need for an effective answer to this problem that promoted this work "How should school pursue its mission with the implementation of the TPE?"

\section{Research Design}

With the main goal of preparing and optimizing the new, richer and integrated technological environment that will be a reality in Portugal, the literature was revised references, aiming to identify the concepts to be used. The practices of six urban secondary schools were observed in their educational component as well as in terms of the administration and management of education supported by the technologies.

We tried to identify the positive and the negative factors that have conditioned the adoption of Technologies, in Portuguese educational system along the years, elaborated and validated a tool (the interview) to observe the best and the not so good practices locally, identified a sample of the universe urban to be studied, gathered the information and analyzed the results to product a solution.

\subsection{Literature}

The object of study in the present work, the process of literature review was identified and the area of activity was defined. This was because there are many approaches 
regarding technology in educational context perspectives. Aware of the importance of literature review in the influence of the final work -3 important dimensions were identified to frame the guideline of the literature to this work.

- Identification of weaknesses and threats of technology implementation in an educational context.

- The impact generated by the introduction of TIS (Technology and Information System) in educational context.

- Guidelines by future care for international exchanges of information on the state of the art of research, development and implementation of scholar information system.

The resulting information collection process, provided information to the interviews design, the results interpretation, and the adopted solution. The information comes mainly from publications of three entities GEPE, BECTA and ITEM. (GEPE, Statistics office of Portuguese Ministry of Education - BECTA, British Educational Communications and Technology Agency - ITEM, Information Technology in Educational Management, the Workgroup 3.7 of Technical Committees 3:Education of International Federation for Information Processing).

\subsection{Definition of the Sample}

Regarding the definition of the set of secondary schools selected for interview requests (sample), the number of schools within the city of Porto was, in the first place, defined. From this total number, 10, we selected 6.In this, 2 are TPE pilot schools, which in turn are from a total of four schools nationwide. They were chosen because they are schools with an educational background that is complementary to and covers the entire educational offer of the Portuguese education system. They also cover the entire urban area and across its social economic impact. The secondary schools Carolina Michaelis, Rodrigues de Freitas, Filipa de Vilhena, Artistic Soares dos Reis, Clara de Resende and Fontes Pereira de Melo were selected for the interviews.

\subsection{The Information Locally Selection Tool - The Interview}

The local observation went from gathering qualitative information to consolidate or weaken the trust in the problems within the revised literature, for the practices to implement the technologies in the educational system. The collection of information was done with the help of face-to-face interviews to the leaderships with top responsibilities in schools - the Director or the responsible for the technologies. The interviews lasted for about 120 minutes, from March to May 2009 and were set to four Directors, all with over 20 years careers, of the schools involved and two responsible for the technologies with more than 15-year careers. They were asked to give their views on the school policies according to six parameters:

Q1- AWARENESS OF THE INTERVENTION OF THE TPE to the school environment and provide an initial approach to the intervention of TPE in schools and their awareness to this fact. 
Q2-RECRUITMENT AND MOBILITY OF THE THEACHERS/ TEACHING STAFF CAUSED BY THE TPE, enquire whether the situation of having a better technologically equipped school makes it more difficult to recruit appropriately and also if the fact that moving to a technologically richer environment will involve the mobility of teaching staff.

Q3- THE PROBLEMATICS OF COMMUNICATION, seeking information about communications seen in the context of interpersonal verbal communication: The way the message is sent to all community, horizontally or vertically to the organization, whether at the level of broadcasting of news or in the transmission of information on a more or less urgent basis.

Q4- THE MANAGEMENT OF THE LEARNING PROCESS, trying to identify innovative areas in the management and fostering of practices. Gather information on innovative and differentiating practices.

Q5- IF THERE IS RESTRUCTURING OF THE EDUCATIONAL PROJECT, study the underlying reorganization of educational projects in richer technological contexts.

Q6 - THE NEED FOR THE MANAGEMENT OF TIS - look for information regarding the relation of community with technology, the concern with the integration of information, better analysis of information on the use of coordinated support for the learning process.

\section{Results and Decision for a Strategic Plan}

\subsection{The Results}

The information gathered was dealt so as to retain, diagnose and give information in the areas selected and in the context of the literature review. Question 1 asked the interviewed about their awareness to the intervention of the TPE. The problematic identified transversally by all the interviewed was the resistance shown in all the processes of change [2], it was identified in all six schools the usual barriers to the process of implementing the TIS [3] developed so far as a concern of the implementation of the TPE. The following are, in short, the common barriers identified:

- All representatives reported personal resistances of various natures-knowledge, motivation, and empathy with the technologies.

- All representatives identified the access to technologies, such as technical factors and factors causing resistance, the availability of reliable and stable technologies, whether at the network level or at the level of equipment in the classroom.

- All representatives expressed concerns with the need for training and education in Information Technology to monitor the process.

On question 2 all the inquired admit altering the teams that have been working with technologies in the management of education at school level, however no school has provided yet, in a conceptual shape, the final solution for the teams. 
On question 3 all schools identified the use of e-mail as a reality. However only one school has that service on adequate machines thus solving a problem identified by the other schools:

- All identified problems in communication, which should be monitored, in such a way as to ensure the efficiency in the two-way reception of communications. There must be proof data elements on this.

In what question 4 is concerned, managing the teaching-learning process, all schools have technology to support the process. All the inquired answered that:

- The use of information resources as an aid to administrative/pedagogic tasks is a reality. All have/use LMS (Learning Management System) Moodle, and student's management software, but none of the previous is integrated.

- Information technology is schools means, at the moment, unstructured informatics networks of support to user that range between the 600 and the 1900 users, they have LMS, access to the Internet providers that go from 1 to 3 , they are at the Web and have several management applications (administrative/pedagogical) without any of them being integrated [3].

One realizes that computers are used more often as a helping tool for individual tasks than to offer support to promote teamwork. There are applications that gather information transversally to the work teams but fail in the connection and communication between them.

On question 5 the directors or the responsible for the technologies were asked to state their opinion, on the school intention to restructure the educational project, as a response to the intervention of the TPE.

- In all the schools there were different readings, sensitivities and perspectives of the problem.

- All the interviewed stated that the legislation demands a revision of the educational project of the school at the beginning of the four year cycle that follows the one about to end now.

- However no school suggested possible paths for the revision of the educational project.

Lastly question 6, which is considered to be the most important as it frames all the process of control coordination of the Technologies and Information Systems - the need for TIS management.

- All the interviewed answered in a superficial way, merely interpreting technical reasons, revealing lack of an integrated and leveraged of global indicators for the management of education.

- All refer to the difficulty in having the material usually operational.

- The schools state that they have specific and independent equipment/ software for the administrative processes. Hardware - PCs, informatics network and access to the Internet. Software - Applications for Human Resources, Inventory and Administrative Management.

- It was mentioned by all schools but one, that the administrative tools, are still being used by a reduced number of processes. 
Based on the processed information, collected through the instruments used, we can state that using computing resources as an aid to pedagogical and administration tasks is a reality in the schools surveyed. However, computers are used more as a help to individual work than as a means to provide teamwork. There are thus applications that collect information transversally to the work teams but fail in the coordination and communication among them.

The existing TIS may be regarded as tailored to the needs of each individual. There is no standard model for the flow of information, hence resulting in a wide variety of representations of information and an inefficient communication. Schools are still in early stages of the route [4] to the schools information systems.It can also be seen that there isn't an overview of TIS in schools, which resort to ad hoc solution with no major concern for integration, such as the disintegration of information [5]. The lack of such a global vision has compromised the preparation of integrated development plans, whether for the purchase of hardware and software, or in the training of human resources. So in the new context, it's advisable to the schools, to keep up with planned to the process. There must be a strategic orientation.

\subsection{The Adoption of a Strategic Model}

The new technological environment brings structured networks with integrated transverse tools and offers collaborative work platforms. This whole new environment has brought important changes in the objectives of organizations, relationships with the community, and internal operations. These systems are called strategic systems [6]. With the implementation of the TPE there is a new reality for TIS in schools. A technological environment, richer and more structured, must be addressed by the community in a well thought out and planned manner with the weight and the strategic orientation that the process of change requires and needs. That is what happened in this case, based on the information collected, it was defined a strategy and aligned the school with its implementation. The best practices on information technologies in education, promote values of strong strategic planning [7].

The barriers to its use, which are the main weaknesses previously identified lead to decide for a strategic direction that could assure a stable, efficient and reliable technological infrastructure as a basis domain. Thereafter that strategy should operate in the 6 areas designated as strategic (Figure 2), namely;

- Dimension area of the teaching-learning process, in order to approach both sides (learning and teaching).

- Administrative dimension, an approach to seek the construction integrated reports of school indicators, so as to increase the efficiency and effectiveness of school and education management.

- An area services dimension capable of opening the school to the community and provide support for innovative activities, able to generate change from a support point of view to research and professional development practices.

- In communications, to be applied in a perspective of interpersonal verbal communication, with a disseminating or targeting nature. 


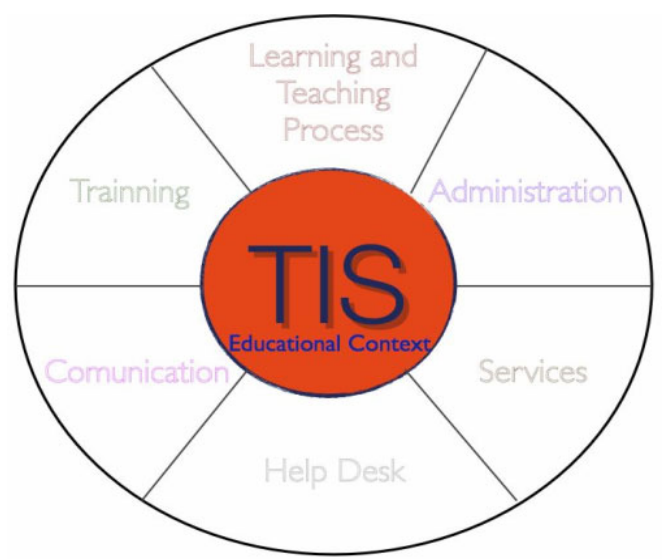

Fig. 2. Strategic orientation to the school

- A monitoring field, with training concerns but with predominant training and monitoring activities of proximity.

- A Technological area with the establishment of a technical filed of global skills.

In order to approach this transversal dimension to the whole school it is advisable that the teams involved in the monitoring process in schools are themselves also restructured. This team works under the guidance of the strategic plan designed for that purpose and which is implemented through action (business) plans to be developed yearly with projects or measures for each area. The monitorization and evaluation of the process has the same framework and aims to make an evaluative and iterative monitoring [8] of the whole process of the implementation of the TPE in schools.

\subsection{Monitoring and Assessment of the Solution}

The assessment, which is the next stage, will determine whether the strategic direction is working or in need for adjustments since the objectives and strategies will be reviewed periodically to ensure their contemporaneity [9]. In this context, an evaluation of an Annual Action (business) Plan will be made in order to identify the strengths and weaknesses and to make adaptations and adjustments in two stages: in the middle of the semester and a final assessment at the end of the school year.

The factors that will be evaluated depend on the purpose of the evaluation itself. We are aware that this cannot focus exclusively on quantifiable results, as some will have resulted in the acquisition of non-measurable skills or knowledge. We will take into account factors that may influence the results, such as the inadequate means or methods, failures problems resulting from equipment and logistics. It is important to bear in mind that the assessment is not limited to the detection of differences between the expected objectives and the results achieved, but above all it is a reflexive process on the Plan itself. The following Instruments (table 2) of Evaluation \& Assessment Objects were defined: 
Table 2. Instruments of evaluation and evaluation objectives for the strategic plan

\begin{tabular}{|c|c|}
\hline INSTRUMENTS & GOALS \\
\hline $\begin{array}{l}\text { - Formal and informal contacts with teachers, students } \\
\text { and non-teaching staff }\end{array}$ & \multirow{7}{*}{$\begin{array}{l}\text { - To observe } \\
\text { resulting materials; } \\
\text { - Observe } \\
\text { management } \\
\text { efficiency } \\
\text { - Development of } \\
\text { ICT skills; } \\
\text { - Monitor New } \\
\text { methods of work; }\end{array}$} \\
\hline - Analysis of materials; & \\
\hline - Measurement for quality of material produced ; & \\
\hline - Questionnaires. & \\
\hline - Evaluation Criteria and Indicators: & \\
\hline - Usage statistics; & \\
\hline - Usage rates; & \\
\hline
\end{tabular}

\section{Conclusions}

Later in this work we assume clearly to be facing the most important intervention in technologies and information systems of the educational system in Portugal.

To position school in this approach it was developed a model to go along with the implementation of the TPE in school which comprises a Strategic Plan, the definition of its implementation through the Annual Action (business) Plans (the make it happen), its monitoring and evaluation Tools. The adoption of a solid strategic plan for TIS is a demonstration from schools, through their leaders and the wide educational community, that the ICT efforts are real and sincere and that the strategy is the expression of a collective will [7]. It is also a clear indicator that the school is willing and capable of evolving its most complex features to levels and results that we are pursuing and hope to attain (Table 3):

Finally the results we will achieve will, undeniably be the teaching benefits, learning benefits and management benefits. This work requires continuity and endurance in its monitoring and readjustments, which is the path we will follow, working on the indicators and the iterative process of monitoring and evaluating.

With TPE technology was brought to school on a massive scale, not as a lifting product, but to improve the quality of what has always been done in schools: teaching and learning. However a new era means a new paradigm. Past is the industrial age in which the school provided the custody, the setting of behavioral rules, ensured cognitive development, socialization and selection for the era of knowledge where the shift is centered in the learning in a school aiming at the building of knowledge - of the practices (doing), of thought (as experience), community (belonging), identity (becoming) [10]. 
Table 3. Expected Results

\begin{tabular}{|l|l|}
\hline \multicolumn{1}{|c|}{ EXPECTED SHORT-TERM RESULTS } & \multicolumn{1}{c|}{ EXPECTED HALF TERM RESULTS } \\
\hline Increased autonomy of the use of IT & Increased autonomy of the use of IST \\
\hline Use of digital content in teaching & $\begin{array}{l}\text { Production of materials and knowledge } \\
\text { supported IT }\end{array}$ \\
\hline Promotion of digital assessment & Collaborative work on digital platforms \\
\hline Propagation of digital portfolios & $\begin{array}{l}\text { Participation in projects outside the } \\
\text { school }\end{array}$ \\
\hline Improve levels of communication & $\begin{array}{l}\text { Providing more and better school } \\
\text { information }\end{array}$ \\
\hline $\begin{array}{l}\text { Encourage the acquisition of ICT } \\
\text { skills }\end{array}$ & \\
\hline
\end{tabular}

The use of technology in education is generating change before which Portugal should not have the sole attitude of observer. One of the facts shown by this study is that TPE certainly wants to correct the existing technological gaps between schools. However, correcting these imbalances is not enough on the evolutionary path to work on the multiple displays [11]. It is necessary to develop a technological culture in Portuguese schools that sets schools free from the use of school bags filled with books, notebooks, assessment records and pencil cases; A culture that generates motivation with the support of technologies and develops self-esteem; A culture that conveys a collective will in the application of the potential use of technologies in education and in the education system. This is where the applicability of TPE should start on the ground, that is, in schools. Developing 'the will' to enable and create a good collective use. The will such began to as the attitude of the four phases of the Management Information Systems [12] - Willing, Thinking, Making, Using.

In an era where technology and education congregate and integrate, managing education is to have effective and efficient access to information to support the process of decision-making in due time. We need technology management and information systems for the production information process; it is necessary to introduce management information systems professionals [13] to have added value in information. The information provided by integrated tools support for the decision making process, the ability to obtain the production of reports and mapping of indicators of educational practices and related support. In the knowledge era, the quality of education is proportional to the quality of TIS. In the knowledge era, the quality of the educational process is structured and leveraged by the TIS. 


\section{References}

1. Tatnall, A., Pitman, A.: In: Selwood, I.D., Fung, A.C.W., O'Mahony, C.D. (eds.) Management of Education in the Information Age: The Role of ICT, pp. 73-82. Kluwer Academic Publishers, Dordrecht (2003)

2. BECTA: A Review of the research literature on barriers to the uptake of ICT by teachers (2004), http: / / partners . becta.org.uk/uploaddir/downloads / page_documents/research/barriers.pdf

3. GEPE, em Estudo de Diagnostico: A modernização tecnológica do sistema de ensinoem Portugal. Gabinete de Estudos e Planeamento Estatístico. Lisboa (2007)

4. Visscher, A.J., Wild, P., Alex, Fung, C.W.: Information technology in educational management: synthesis of experience, perspective and future Research on ComputerAssisted School Information Systems, pp. 3-18. Kluwer Academic Publishers, Dordrecht (2001)

5. Baker, G., O’Mahony, C.D., Selwood, I.D., Strickley, A.: Evolution of Information Technology in Educational Management. In: Tatnall, A., Visscher, A., Finegan, A., O’Mahony, C. (eds.) IFIP International Federation for Information Processing, vol. 292, pp. 189-199. Springer, Boston (2009)

6. Laudon, K.C., Laudon, J.P.: Management Information Systems: A Contemporary Perspective. Macmillan, Basingstoke (1990)

7. O’Mahony, C.D.: IFIP International Federation for Information Processing. In: Tatnall, A., Visscher, A., Finegan, A., O’Mahony, C. (eds.) Evolution of Information Technology in Educational Management. IFIP-AICT, vol. 292, pp. 15-22. Springer, Boston (2009)

8. Currie, W., Galliers, R.: Rethinking Management Information Systems: An Interdisciplinary Perspective. Oxford University Press, Oxford (1999)

9. Selwood, I.D., Drenoyianni, H.: Information Technology in Educational Management for the schools of the future: TC3/WG 3.4. In: Fung, C.W. (ed.) IFIP International Conference on Information Technology in Educational Management (ITEM), pp. 98-116. Springer, Boston (2009)

10. Miller, R.: Lisbon Forum on innovative approaches to ICT in education. Presentation available online, Xperiodox futures consulting (2009), http: / / www.rielmiller.com/papersmethods.html

11. Passey, D.: IFIP International Federation for Information Processing. In: Tatnall, A., Visscher, A., Finegan, A., O'Mahony, C. (eds.) Evolution of Information Technology in Educational Management, vol. 292, pp. 69-82. Springer, Boston (2009)

12. Amaral, L.: Da Gestão ao gestor de sistemas de informação: Expectativas fundamentais no desempenho da profissão. em Sistemas de Informação Organizacionais, Editores: Luís Amaral, Rodrigo Magalhães, Carlos Campos Morais, António Serrano, Carlos Zorrinho. Edições Sílabo, 51-70 (Portuguese Source) (2005)

13. Lange, A., Breiter, A.: IFIP International Federation for Information Processing. In: Tatnall, A., Visscher, A., Finegan, A., O'Mahony, C. (eds.) Evolution of Information Technology in Educational Management, vol. 292, pp. 1-14. Springer, Boston (2009) 